\title{
EXPERIÊNCIA UNIVERSITÁRIA E AFILIAÇÃO: MULTIPLICIDADE, TENSÕES E DESAFIOS DA PARTICIPAÇÃO POLÍTICA DOS ESTUDANTES*
}

\author{
Marilia Pontes Sposito ${ }^{1}$ \\ Felipe de Souza Tarábola ${ }^{1}$
}

\begin{abstract}
RESUMO: Apresentam-se neste artigo narrativas de jovens estudantes de camadas médias ou estratos populares de diferentes universidades públicas do estado de Sáo Paulo sobre o modo como se relacionam no espaço público político no interior da universidade. A pesquisa qualitativa a respeito dos desafios comuns enfrentados por esses estudantes indicou a existência de diversas formas de atuação nos vários momentos da experiência universitária. A reflexão acerca das tensóes entre engajamento, militância e apatia política é apresentada aqui por meio da constituição de três grandes tipos de afiliação desses indivíduos ao agir coletivo, com o objetivo de ilustrar as novas formas de ação dos estudantes universitários contemporâneos.
\end{abstract}

Palavras-chave: Ação coletiva. Jovens universitários. Política. Esfera pública. Afiliação.

\section{UNIVERSITY EXPERIENCE AND AFFILIATION: MULTIPLICITY, TENSIONS AND CHALLENGES OF THE STUDENTS' POLITICAL PARTICIPATION}

ABSTRACT: In this article, it is presented the narratives of young students of middle-class or popular social classes from different public universities from the state of São Paulo, about how they relate themselves in the political-public space in the university. The qualitative research about the challenges faced by these students has indicated the existence of several course of action in the various moments of the university experience. The considerations over the tensions among engagement, militancy and political apathy are exposed here through the constitution

\footnotetext{
*Além dos dados oriundos do projeto de pesquisa Estudos de juventude e sociologias do individuo: elementos teóricos e empiricos para a compreensão dos processos contemporâneos de individuação na sociedade brasileira, coordenado pela Profa. Marilia Pontes Sposito com bolsa de produtividade em pesquisa do CNPQ, o artigo toma como base resultados da pesquisa de doutorado de Felipe de Souza Tarábola intitulada Aspirantes: desafios de estudantes da USP egressos de escolas públicas no contexto do novo tensionamento político-social brasileiro, realizada na FEUSP sob orientação da Profa. Marilia Sposito.

${ }^{1}$ Universidade de São Paulo, Faculdade de Educação - São Paulo (SP), Brasil. E-mails: sposito@usp.br, fst@usp.br

DOI: 10.1590/ES0101-73302016166158
} 
of three great types of affiliation of these individuals while acting collectively, with the purpose of showing new ways of action of the contemporary university students.

Keywords: Collective Action. Young students. Politics. Public Sphere. Affiliation.

\section{L'EXPÉRIENCE UNIVERSITAIRE ET L'AFFILIATION: MULTIPLICITÉ, TENSIONS ET DÉFIS DE LA PARTICIPATION POLITIQUE DES ÉTUDIANTS}

RESUMÉ: Cet article présente des récits de jeunes étudiants des classes moyennes et des milieux populaires de différentes universités publiques de l'état de Sáo Paulo en ce qui concerne la manière dont ils se rapportent dans l'espace publique politique au sein de l'université. La recherche qualitative à propos des défis communs auxquels sont confrontés ces étudiants a indiqué l'existence de plusieurs formes d'action dans les divers moments de l'expérience universitaire. La réflexion sur les tensions entre l'engagement, le militantisme et l'apathie politique est présentée ici à travers la mise en place de trois grands types d'affiliation de ces individus à l'agir collectif, afin d'illustrer les nouvelles formes d'action des étudiants universitaires contemporains.

Mots-clés: Action collective. Jeunes étudiants. Politique. Sphère publique. Affiliation.

\section{Introdução}

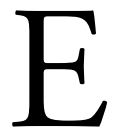

ste artigo é decorrente de pesquisa qualitativa realizada com aproximadamente 20 jovens estudantes de graduação de diferentes cursos de universidades públicas do estado de São Paulo (SP), como Universidade de São Paulo (USP), Universidade Estadual de Campinas (Unicamp), Universidade Federal de São Carlos (UFScar) etc., originários das camadas populares e dos setores médios da sociedade brasileira.

Por meio de um leque variado de estudantes, a investigação buscou compreender os desafios presentes em suas vidas em um importante momento de afiliação à experiência universitária. Entre os temas que recobrem os desafios por eles narrados, as relaçóes com a esfera pública, o agir coletivo e a prática política apareceram, de modo espontâneo, como eixos importantes. Em um contexto de franco individualismo (mas não egoísmo), chama atenção a construção da sociabilidade desses jovens, destacadamente no que diz respeito às múltiplas e variadas formas de percepção da atuação no âmbito público-político. 
Partindo entáo, indutivamente, do que relatam esses estudantes universitários é que se colocam as ambiguidades e tensóes da participação, do engajamento e da militância em perspectiva neste artigo, com o objetivo de apresentar uma reflexão sobre o que é nos dias atuais relacionar-se com a esfera público-política, os desafios da afiliaçáo às diversas formas do agir coletivo e suas tensóes no espaço universitário. Com o intuito de abordar as múltiplas maneiras de participação, em vez dos termos mais convencionais de engajamento ou militância, por exemplo, elegemos o conceito de afiliaçáo no sentido cunhado pelo sociólogo Alain Coulon (2005), como incorporaçẫo e naturalização das práticas e dos códigos de funcionamento de uma instituição a ponto de conseguir conhecer e transgredir autonomamente as regras do jogo.

Trata-se, portanto, de um estudo realizado com base em entrevistas compreensivas (KAUFMANN, 1996) que visa apreender os atuais desafios vividos pelos universitários e como esses estudantes respondem a eles. Apesar de ter aparecido destacadamente nas análises do material colhido a menção feita pelos jovens a diversos tipos de engajamento em associaçóes, coletivos, movimentos e outras formas de ação coletiva, a discussão apresentada aqui ainda se encontra em estágio inicial e tem por propósito ilustrar alguns dilemas presentes nos diferentes caminhos que conduzem a modos diversos de atuação na esfera público-política na contemporaneidade.

\section{Diversidade, permanências e mudanças nas práticas políticas estudantis}

A emergência pública e política dos jovens brasileiros em meados do século XX ocorreu sobretudo no interior da universidade, protagonizada pelos estudantes universitários na luta contra a ditadura e as políticas educacionais que afetaram a vida universitária naquela conjuntura. Desse período, os marcos empíricos e teóricos de Marialice Foracchi, Octavio Ianni, entre outros ${ }^{1}$, foram fundamentais para a compreensáo dos dramas contidos na experiência do radicalismo político de jovens das denominadas classes médias em sociedades dependentes (IANNI, 1968; FORACCHI, 1965; 1972).

Os estudos sobre os movimentos estudantis continuaram a acontecer em décadas posteriores, não obstante o relativo arrefecimento da temática, em parte decorrente da própria crise da ação coletiva desses atores. Tal crise seria oriunda da burocratização das entidades que sobreviveram à luta contra a ditadura, de seu distanciamento diante da maioria dos estudantes considerados apáticos pelas lideranças estudantis, da fragmentação dos grupos e da sua dependência em relação às organizaçôes políticas.

Mas, para os efeitos do que aqui se procura discutir, torna-se fonte de inquietaçáo teórica o reconhecimento da necessidade de ampliar o escopo inves- 
tigativo sobre as novas formas organizativas que nasceram no interior do espaço universitário, a convivência entre modos diferentes de encaminhamento do protesto político, mesclado por novas e tradicionais práticas que configuram os conflitos contemporâneos (BRINGEL, 2009; 2012; GROPPO; ZAIDAN FILHO; MACHADO, 2008).

As inúmeras questóes que se abrem para a pesquisa tornam-se mais complexas se forem consideradas as mudanças sofridas pela sociedade brasileira no período de sua redemocratização que afetaram aspirações e estilos de vida dos jovens e criaram novas oportunidades de acesso ao Ensino Superior, nível de ensino cada vez mais aberto aos setores populares, mediante políticas afirmativas e ofertas de novas vagas em universidades públicas. Observam-se os conflitos e limites da transição para a democracia como sistema político-institucional, porém que vive agora as tensões advindas dos anseios pela participação nas tomadas de decisão governamentais (AVRITZER, 2012; 2013; DAGNINO; OLIVEIRA; PANFICHI, 2006), do desejo de horizontalização das relações (SORJ; MARTUCCELLI, 2008) e da busca da diminuição da desigualdade e ampliação das oportunidades sociais (POCHMANN, 2015; ARRETCHE, 2015) em conjunturas que nem sempre oferecem as condições sólidas das novas demandas. Todavia, também se caracteriza pelo crescimento de associaçóes e pelo adensamento da sociedade civil, a qual, não necessariamente, é marcada pelo pluralismo, pela autonomia, pela solidariedade e pelo impacto na esfera pública, posto que alguns estudos recentes indicam situação muito mais múltipla dos sujeitos coletivos como organizaçôes não governamentais (ONGs) e outras associaçôes, marcada pela heterogeneidade de objetivos, interesses e formas de organização, por diversos tipos de vínculos e relações com o sistema político. Tais formas sofrem diferentes influências do contexto nas suas práticas e formulação política, "desautorizando uma leitura que imprime uma natureza necessariamente democrática desse campo" (LÜCHMANN, 2011, p. 48).

Duas perspectivas, entre outras, podem ser consideradas como eixos importantes para o desenvolvimento da pesquisa sobre jovens universitários e a esfera público-política. De um lado, está a investigação dos coletivos juvenis hoje atuantes em sua diversidade e seu pluralismo, compreendendo aqueles que agregam as entidades estudantis mais tradicionais, as correntes políticas partidárias (SOUSA, 2014; GROPPO, 2016) e os que se reúnem por demandas de reconhecimento, como é o caso dos estudantes negros, grupos feministas e lésbicas, gays, bissexuais, travestis, transexuais e transgêneros (LGBT) etc. As relações entre associações, organizações e democracia são complexas e plurais e não podem ser facilmente generalizadas sem análise das disputas, dos debates e dos conflitos presentes nas efetivas práticas associativas (LÜCHMANN, 2014).

Uma segunda via de entrada, apresentada de modo exploratório neste artigo, reside na tentativa de compreender essas mudanças com base na forma 
como os indivíduos jovens vivem sua experiência universitária nos marcos da sua relação com essa esfera público-política. Estaríamos diante de um desafio histórico e estrutural marcado pela pluralidade dos modos de vida e da diversidade de situaçóes que singularizam as trajetórias individuais nos coletivos no interior de uma miríade de conflitos sociais ao lado de certas reiteraçóes que continuam tratando da questão de modo homogêneo, como se a política e o engajamento fossem expressóes autoevidentes dotadas de significado único por meio de quadros de referência ou de narrativas que já não dão conta dos novos processos históricos que emergem mesmo de maneira não visível.

Em situaçôes históricas que envolvem a complexidade maior dos processos socializadores, sua pluralidade e suas ambiguidades, torna-se importante verificar como os indivíduos agem sobre si mesmos a partir dos constrangimentos e das possibilidades que o mundo social lhes apresenta. Para levar em conta a inscrição dos processos sociais (transformaçóes econômicas, políticas ou culturais) nas existências individuais, aposta-se aqui no estudo do processo de individuação, um exercício teórico que tenta articular as consequências das transformações históricas em uma vida (ou de uma geração), questionando o tipo de indivíduo que uma sociedade fabrica com as respostas que as pessoas apresentam aos desafios inelutáveis que encontrarão ao longo de suas trajetórias, tal como proposto pelo sociólogo franco-peruano Danilo Martuccelli, para quem, em suma, "uma sociologia da individuação se afirma como uma tentativa para escrever e analisar, a partir da consideração de algumas grandes transformações históricas, a produção dos indivíduos" (MARTUCCELLI, 2007, p. 30).

\section{Os indivíduos jovens e a política}

Múltiplos significados compreendem a expressão política. A concepção de que toda socialização seria política, uma vez que a forma pela qual a interiorização das normas sociais atualizaria posições e disposiçóes de classe, sexo e raça, demonstra o sentido amplo que as relaçóes de poder podem obter em uma sociedade (BARGEL, 2013). A insuficiência de uma definição apenas formal da política como conjunto de atividades referidas ao Estado e à regulação legal das relaçóes sociais (LECHNER, 2007, p. 244) não significa tampouco a opção por um alargamento conceitual excessivo da política. Reconhecer que toda ação social tem dimensão política não quer dizer que tudo seja fazer política, mas que o campo que constitui o agir político não pode ser definido sem as peculiaridades históricas que orientam as lutas e interaçóes que se inscrevem na distribuição de poder dos grupos sociais.

Tal perspectiva considera a clássica definição de Max Weber que relaciona o agir político à busca de poder: "Quem participa ativamente da politica luta pelo poder, quer como um meio de servir a outros objetivos, ideais ou 
egoístas, quer como o 'poder pelo poder', ou seja, a fim de desfrutar a sensação de prestígio atribuída pelo poder" (WEBER, 1982, p. 98, grifo nosso). Assim, neste artigo, a expressão politica compreende as relaçóes com os processos de afiliação ou de distanciamento perante as organizaçóes que atuam no espaço público (ELIASOPH, 1998).

No interior de grandes transformações históricas, a emergência das formas sociais que rompem com as tradicionais concepçôes holísticas da vida social e o aparecimento da sociedade de indivíduos (ELIAS, 1994), a formação dos espaços públicos e coletivos e a temática dos engajamentos políticos tornaram-se questóes relevantes para a compreensão da vida social. Como afirma Ion (2012), o individualismo moderno não significa necessariamente domínio do egoísmo, do isolamento e do narcisismo, aspectos presentes nas análises de diversos autores. Para o teórico, o processo que inaugura na modernidade ocidental os direitos humanos e a busca da emancipação e autonomia dos indivíduos, em detrimento de sua subordinação sem mediações a coletividades, constituíram um conjunto de princípios que alimentaram o pensamento socialista e libertário desde o século XVIII (ION, 2012).

Assim, ao tratar do que significa agir coletiva e politicamente em contexto de franco individualismo, a análise não incide necessariamente sobre o isolamento e o egoísmo, sobretudo quando se quer discutir as relaçóes dos jovens com a denominada esfera público-política. Embora valha o alerta feito por Nina Eliasoph a respeito da produção da apatia entre norte-americanos em contextos de enunciação públicos, não se pode ignorar a premência do mundo político, do qual não se pode escapar, já que suas discussões e decisóes permeiam a vida humana, queiramos ou não. Por isso, o silêncio político é ativo. Ele ocorre ainda que as pessoas estejam descontentes e não achem que está tudo certo do jeito como está; ele ocorre porque muitas vezes a discussáo política parece não caber na esfera pública (ELIASOPH, 1998).

Dessa forma, considerando a pertinência de recentes análises como as empreendidas pelo sociólogo Martuccelli acerca da especificidade da individuaçáo e dos desafios enfrentados na América Latina, por conta da fraqueza das instituiçốes sociais, o indivíduo aqui entre nós se torna um hiperator relacional, assumindo para si (e contando com suas relaçóes familiares e amicais) tarefas que em outros contextos (como na Europa e nos Estados Unidos) ficam a cargo das instituições, o que torna, assim, a implicação, a participação, a valorização do laço social um aspecto fundamental para a sua própria constituição (MARTUCCELLI, 2010).

No início dos anos 1980, momento de luta pela transição democrática na América Latina, Norbert Lechner já apontava importantes transformaçôes na América Latina tendo em vista os processos de individualização então observados: 
Uma das mudanças mais importantes - considerando a tradição comunitária da América Latina - é a crescente individualização. $\mathrm{O}$ indivíduo se desprega dos vínculos e hábitos tradicionais que, por sua vez o "constrangiam" e o protegiam. Esta "saída ao mundo" faz parte de um processo de emancipaçáo que permite ao indivíduo ampliar seu horizonte de experiências, incrementar suas capacidades de participar na vida social e desenvolver suas opções de autorrealização. Sem dúvida nem todos conseguem usufruir das oportunidades. Considerando que não há indivíduos à margem da sociedade, a individualização depende das opçóes e dos recursos que oferece a sociedade em determinada época histórica... nossa sociedade se torna cada vez mais complexa e diferenciada, crescem as possibilidades, mas também as dificuldades para a autodeterminação do indivíduo (LECHNER, 2007, p. 472).

O esforço analítico requer, então, olhar para o complexo momento pelo qual passa o Brasil, um processo que pode ser caracterizado pelo termo democratização da sociedade (AVRITZER; SANTOS, 2002; TILLY, 2013), prenhe de criação de dissenso (RANCIÈRE, 1996) e tentativas de invenção de novas formas de disputa (LEFORT, 1983) por aqueles que desconfiam do poder instituído (ROSANVALLON, 2006) e agem contra dois monopólios: o da vida pública por governos oligárquicos e o da riqueza sobre a vida comum (RANCIĖRE, 2014). Nessa perspectiva, a intensificação do debate público que politiza e polariza as posiçóes individuais, exacerbada pela multiplicação exponencial dos usuários das redes sociais, exige certa prudência interpretativa. Deve-se evitar aquilo que JeanClaude Passeron indica como "excesso de velocidade" na análise para configurar a novidade trazida pela conjuntura que leva a afirmaçóes típicas do "nunca antes", mas igualmente é preciso fugir do tentador viés interpretativo que encontra na investigação "sempre o mesmo" (PASSERON, 1987).

Assim, o objetivo deste trabalho foi, partindo desse quadro brevemente esboçado, apresentar uma reflexão sobre as narrativas de alguns jovens estudantes universitários graduandos de diferentes cursos de instituiçóes de ensino superior públicas do Estado de São Paulo que convivem de modo próximo ou mais distanciado em associaçóes de matizes, objetivos, configurações diversas para contribuir com o debate a respeito do atual significado e experiência de engajamento juvenil nesse panorama de declínio de certa ideia de militantismo político por um lado (BAQUERO \& BAQUERO, 2012), no entanto de crescimento de outras formas de atuação na esfera pública em um contexto de individualismo (BECQUET \& LINARES, 2005; ION, 2012).

Longe da anunciada apatia política, discurso muitas vezes feito em termos de comparação entre geraçôes (CICHELLI, 2009; MUXEL, 1997; 2008), essas entrevistas demonstram a busca pela interação com os pares e participação dos univer- 
sitários em diferentes associaçôes como mecanismo de inserção na vida coletiva de uma sociedade com novas configuraçóes, com uma nova consistência que aponta possibilidades e constrangimentos aos indivíduos (MARTUCCELLI, 2005).

A reflexão sobre o modo como esse conjunto específico de indivíduos relaciona-se com a esfera pública e política propicia, assim como destacou Melucci (1997) ao caracterizar a juventude como grupo social por vezes portador da mensagem do futuro, a construção de outras questóes no que concerne à ação coletiva e à maneira como se constituem os indivíduos na sociedade atual.

\section{As aflições da afiliação e dos engajamentos entre jovens universitários}

Para refletir sobre a participação contemporânea em grupos, coletivos, associaçóes, movimentos organizados e, até mesmo - por que não? —, sindicatos e partidos políticos, têm-se em vista as consideraçóes acerca de militância e engajamento feitas pelo sociólogo francês Jacques Ion em uma série de estudos a respeito da transformaçáo da vida associativa, sendo esta última caracterizada por ser cada vez menos atrelada às pertenças originárias herdadas e comunitárias (como a família e grupos profissionais e locais), ser livre em relação a obrigaçóes jurídico-institucionais, ter posição crítica no tocante aos mecanismos de delegação, desejar resguardar sua própria reflexão e direito de fala individual para além das decisóes e dos princípios coletivos, enfraquecer processos de formação interna das organizaçôes etc. (ION \& RAVON, 1998).

Ao contrário, o engajamento pessoal dos indivíduos só ocorre quando se consegue resguardar a própria autonomia e identidade, algo que acontece cada vez mais em agrupamentos de redes de indivíduos voltados ao cumprimento de uma tarefa (ou defesa de um direito) específica. Em vez de uma adesão a uma causa transcendente e projetada em um porvir, seriam mais comuns os engajamentos efêmeros, rescindíveis a qualquer momento, duráveis tanto quanto uma tarefa a cumprir. Alguns coletivos de jovens se caracterizam dessa forma, chegando com frequência a quase prescindir de reunióes e encontros presenciais, uma vez que cada indivíduo, resguardada sua iniciativa pessoal, pode permanecer anônimo em sua atuação a distância, tornando invisível a própria unidade social do grupo, pois em algumas situaçóes os filiados ou associados podem até mesmo nem conhecer um ao outro (ION \& RAVON, 1998).

Nessa militância em busca de resultados mais concretos (quase um "idealismo pragmático"), norteada pela sensação de risco de perder direitos, benefícios ou mesmo posiçóes sociais (aquilo que tão bem foi denominado de inconsistência posicional por Araujo \& Martuccelli, 2012) e marcada pela constante reflexividade sobre a ação, os indivíduos exerceriam sua vontade de participação de modo cada vez mais horizontal (ION, 2005). 
Por essa razão, ganha destaque o uso da internet como modelo de rede horizontal de participaçáo direta (dada a enorme desconfiança aos mecanismos de representaçáo e aos procedimentos de delegaçáo). $\mathrm{Na}$ internet, todos os membros têm direito à fala e permite-se um engajamento distanciado e emancipado (GRANJON, 2001). O balanço de algumas pesquisas da perspectiva chamada etnografia do político retoma, entre outros, essa discussão concernente à participação em experiências coletivas amparadas em dispositivos científicos e tecnológicos, como a participação eletrônica via Wikis, Twitter, Facebook, YouTube e na blogosfera, além de suas consequências para a vida democrática. Isso se dá porque o sentido de engajamento é de outra ordem, considerando mesmo aquele em que ocorre certa evaporação do político, com indivíduos agindo em seus próprios interesses e defendendo privilégios (os chamados movimentos NIMBY, not in my back yard), mas que não podem ser facilmente identificados como retirada dos indivíduos à esfera privada por conta da dominaçáo simbólica ou da falta de conscientização em virtude da alienação, já que há certa racionalidade em situaçôes de rejeiçâao de participação (CEFAÏ et al., 2012).

Os tipos de engajamento são múltiplos; compreendem militantes à moda "tradicional", envolvidos de maneira duradoura em sindicatos e partidos políticos (SAWICKI \& SIMÉANT, 2011; BRENNER, 2014; SPOSITO, 2014), e novas modalidades analisadas por Ion (2012) por meio das metáforas do post-it, de modo a caracterizar adesões mais provisórias.

Para ponderar sobre o modo como alguns jovens universitários narram sua experiência em diferentes instâncias da vida associativa de nossa sociedade, apresentam-se a seguir algumas figuras expressivas das relaçóes dos estudantes com essas organizações, suas lógicas, seus princípios e suas práticas, com o intuito de verificar mais detidamente essa importante dimensão do laço social em um momento de singularizaçáo crescente das trajetórias individuais, por demanda de autonomia e de tensōes entre as gramáticas que orientam as práticas coletivas público-políticas, as molduras e as narrativas que as justificam. Ressalta-se, também, a peculiaridade do ambiente universitário das instituiçôes públicas e suas organizações estudantis e sindicais envolvendo docentes e funcionários. Nesse mundo já existe um conjunto de regras muitas vezes tácitas e molduras que sustentam a prática política que é preciso conhecer para ser capaz de lidar com elas e eventualmente afiliar-se (COULON, 2005).

\section{A inserção na esfera público-política antes do ingresso na universidade}

A primeira figura que emerge das narrativas de parte dos jovens entrevistados decorre da experiência de participação e de engajamento em coletivos e movimentos em momento anterior à entrada na universidade. Assim, a des- 
coberta da vida pública e política é anterior ao ingresso na universidade, e esses jovens adentram no ensino superior com essa bagagem inscrita em suas trajetórias. Nesse grupo estáo reunidas as narrativas de rapazes e moças que participaram da criação de coletivos nos bairros populares, seus locais de moradia, por meio de atividades culturais, grupos de estudo, entre outros. Muitas vezes a experiência de vida associativa nasce da adesão temporária às denominadas culturas juvenis, como é o caso, por exemplo, da participação nos grupos de orientação anarcopunk (KEMP, 1993), que possibilitam a ampliação dos horizontes políticos pela descoberta do anarquismo e, em seguida, favorecem o engajamento em novos movimentos. Os grupos locais com atividades culturais, pequenos coletivos para estudo orientados por professores dedicados de escolas públicas, podem estar presentes nessas formas de engajamento.

Um elemento importante presente nessa primeira figura típica decorre também da recente descoberta de maiores possibilidades de acesso ao ensino superior advinda da convivência com ativistas estudantes universitários. Alguns jovens relatam o acesso a um primeiro curso universitário, em geral uma instituição privada, facilitado pelas políticas educacionais dos últimos dez anos. Mas é a própria experiência do engajamento que amplia os horizontes, e a ideia do direito ao acesso a uma universidade pública apresenta-se como um desafio. Alguns jovens chegam a interromper os estudos já iniciados para desenvolver um intenso trabalho de preparo pessoal para enfrentar os vestibulares em universidades públicas, escolhendo outras carreiras. Essas iniciativas estão marcadas por conflitos e tensões com o grupo familiar e exigem um grau de persistência pessoal e de autoconfiança de modo a evidenciar para si mesmos e familiares sua capacidade.

Esses jovens adentram a vida universitária com uma expectativa favorável à participação, com predisposição a se integrar nos coletivos da vida estudantil. Essa disponibilidade, no entanto, acontece em meio a tensóes que derivam de múltiplas situaçóes de conflito. De um lado, as dificuldades da convivência com aqueles que são militantes, muitas vezes, de classes médias. Nesse caso, a posiçấo social de origem e as marcas das identidades étnico-raciais são vividas com sofrimento na medida em que os outros, seus pares, reiteram, mesmo que inadvertidamente, as discriminaçôes, que podem aparecer sob a forma de jocosidade e de cordialidade mesmo em condições amigáveis. Entre o enfrentamento para manter o engajamento e o silêncio ativo que leva ao retraimento existe uma fronteira tênue, produzindo tensão permanente nesse momento da experiência universitária.

Outros desafios para a afirmação da singularidade advêm ainda da capacidade de enunciar o dissenso no momento do debate público nas reunióes e assembleias diante de posições discordantes que não são das lideranças organizadas. As regras democráticas para o debate e a aceitação do pluralismo de posiçóes nem sempre se dão, e as polarizaçôes e os confrontos podem provocar rupturas. Logo, 
o engajamento anterior à entrada na universidade náo aparece como condiçáo automática para novas afiliações, exprimindo um conjunto de alternativas possíveis. Pode ocorrer a manutençáo dos laços e engajamentos anteriores e externos à universidade como ponto de equilíbrio e de ancoragem para a superação das dificuldades que se apresentam na militância estudantil universitária. Todavia, as narrativas indicam, muitas vezes, uma relação mais reflexiva e distanciada de todos os grupos organizados, que não pode ser considerada apenas passividade, uma vez que a presença em algumas mobilizações ou eventos políticos ainda é mantida.

\section{Afirmações identitárias em busca de reconhecimento e respeito no meio universitário}

O segundo tipo que se revela nas narrativas incide sobre jovens, homens e mulheres, que buscam na experiência coletiva explicitar e afirmar orientaçôes identitárias, muitas vezes impedidas ou dificultadas em sua manifestaçáo na esfera familiar e local de moradia. Essa experiência aparece na fala tanto de jovens oriundos das camadas populares como das denominadas camadas médias.

Nesse momento do percurso de vida, marcado pelo ingresso na vida universitária, ocorre a busca mais efetiva de autonomia e independência (SINGLY, 2005), e a entrada em coletivos favorece a afirmaçáo dessas identidades que rompem com os modelos normativos dominantes.

Os coletivos de jovens em torno da questão LGBT são recentes, tendo atingido inicialmente os segmentos médios mais escolarizados em meio universitário, mas sobretudo em ambientes virtuais ou organizaçóes da sociedade civil a partir do início dos anos 2000, agregando posteriormente jovens de camadas populares (DANILIAUSKAS, 2016). Nos últimos anos esses grupos começam a ser disseminados no interior da universidade, mas ainda não há um conjunto de estudos que permita conhecê-los com mais profundidade.

Não se trata apenas da reunião para o desenvolvimento de estratégias reivindicativas comuns ou de denúncias das práticas de preconceito e discriminaçấo. Esses coletivos compreendem os processos de afirmaçáo e de reconhecimento de identidades individuais negadas que exprimem dimensóes importantes da subjetividade de moças e rapazes nesse momento do percurso de vida.

Nessas narrativas, o espaço universitário tem se caracterizado como possibilidade de tornar públicas as orientaçóes divergentes das normatividades sexuais e de gênero dominantes. Logo, o envolvimento individual é intenso, porque está em jogo a busca de reconhecimento e a afirmação das singularidades, momento em que os grupos aparecem como suportes importantes (MARTUCCELLI, 2002). Muitos desses coletivos se abrem para o envolvimento em questóes públicas e políticas mais amplas, como pôde ser observado nas mobilizações em torno das 
aprovaçôes dos planos de educação em 2015, quer em nível municipal, quer em nível estadual, quando grupos religiosos se organizaram para suprimir referências às questôes de gênero e homofobia constantes nas primeiras propostas. A imersão nos espaços públicos que disputam posiçóes fora da universidade, em conjuntura que acentua polarizaçóes, discriminaçóes e preconceitos, pode afetar fortemente a subjetividade desses jovens. Não se trata apenas da conquista e afirmação de direitos coletivos para minorias, porém também de modos de engajamento que exprimem feiçóes identitárias importantes.

A face pública das orientaçóes sexuais e de gênero não dominantes expôe os indivíduos em momento ainda inicial de autoafirmação que, muitas vezes, também não encontram ancoragem nem mesmo nos grupos de pertencimento ou de organizaçóes aliadas. Algumas das narrativas de jovens que integram essas afiliaçóes exprimem o sofrimento pessoal tanto no interior desses coletivos diante dos conflitos interpessoais cotidianos como nos momentos do confronto político mais amplo, algumas vezes fora dos muros da universidade. Em ambos os casos, o que está em jogo não é apenas a afirmação de uma posição ou o reconhecimento identitário (HONNETH, 2003), contudo o permanente desafio de afirmar sua condição singular, na chave do respeito (MARTUCCELLI, 2002).

\section{Participação em associações do voluntariado: quando novos estudantes se engajam na retribuição da dádiva}

Assim como Erlich (1998) fez nos anos 1990 no contexto francês, de modo análogo, algumas pesquisas recentes têm discutido a ocorrência de transformação semelhante no perfil dos alunos das universidades públicas do Estado de São Paulo, enfatizando o ingresso de jovens de camadas populares e oriundos da rede pública de ensino (ALMEIDA, 2006; PIOTTO, 2007; TARÁBOLA, 2010; 2015; ALMEIDA; ERNICA, 2015). Sobretudo, para além das questôes acadêmicas e de eventuais prejuízos escolares acumulados anteriormente ao ingresso na universidade, percebe-se que pesa sobre tais novos estudantes uma série de obstáculos para a necessária afiliação à instituição, cujas práticas, códigos implícitos e princípios reguladores não são conhecidos a priori - estando muito distantes da discussão de um habitus escolar (COULON, 2005).

As observaçóes realizadas pelo sociólogo Felouzis (2001) a respeito do processo de adaptação e afiliação dos estudantes às instituiçóes universitárias apresentam outras nuanças às análises feitas anteriormente por Coulon (2005) acerca do processo de afiliação e contribuem para a discussão da vida universitária e ações políticas dos estudantes universitários aqui analisados. Alguns pontos levantados por aquele sociólogo, embora haja grande diferença entre os dois sistemas de ensino, podem encontrar ressonância em instituiçóes tão complexas e diversas como 
as universidades paulistas e seus variados cursos, institutos, departamentos, programas e mesmo vários campi na capital e no interior do Estado.

Para enfrentarem os desafios vividos na chegada ao ensino superior público, adaptarem-se ao espaço, às regras implícitas e rupturas, deixando assim de serem "estrangeiros" à vida universitária, ao mesmo tempo em que devem aprender a lidar com uma organização fluida, na qual as demandas não são precisas, os objetivos são difusos e os meios de alcançá-los fracos, os estudantes precisam definir o tempo, modo e investimento de trabalho pessoal nos estudos. Isso porque a universidade se caracterizaria por ser um contexto de relaçóes transitórias e incertas, marcadas pelo distanciamento com colegas (de perfis muito diferentes e que mudam a cada semestre ou disciplina) e com docentes que não demonstram nutrir nenhum interesse por eles. Tal desinteresse levaria também os estudantes a terem de, frequentemente, lidar com comandas de tarefas pouco coercitivas e muito indicativas, com poucos momentos de avaliação e retornos aos alunos (FELOUZIS, 2001).

Esses julgamentos universitários remeteriam a um aspecto subjetivo de julgamento sobre si, ameaçando portanto a própria identidade dos estudantes que tanto se dedicaram para estar ali, em um momento no qual atravessam um processo de ruptura para tentar se adaptar ao novo contexto. Muitos estudantes lidam com as avaliaçóes universitárias como experiência do desprezo (HONNETH, 2003) e só conseguem atravessar esse processo de reconstrução identitária por meio da adoção de uma tática de investimento em interaçóes e relaçóes interpessoais. Dessa maneira, ressalta-se ainda mais a importância da sociabilidade para além das relaçóes de coleguismo existentes nas aulas para esse caminho de construção de si, como estudante e como pessoa, no interior da universidade. Ou seja, trata-se de buscar uma atividade, uma forma de participação em algum grupo, associação ou coletivo (esportivo, político, acadêmico etc.) para se inserir na lógica da própria universidade, rumo à superação da indeterminação e indefinição dos primeiros momentos de estudos e à formação de uma identidade universitária distante de uma postura meramente liberal de cada um por si.

Mais ainda, para alguns desses jovens estudantes o engajamento se dá em associaçóes e açóes relacionadas à causa da educação de outros tantos jovens de perfil muito semelhante ao deles próprios, uma dádiva ancorada, ao modo proposto por Mauss (2003), em um movimento triplo, de doação, recebimento e devolução. Isso ocorreria devido às razóes que os jovens estudantes pesquisados dariam acerca do próprio sucesso escolar: o mesmo não é visto como mérito apenas individual, mas de toda uma cadeia de múltiplos incentivos e investimentos próprios, familiares e também de amigos, colegas, professores e mesmo do próprio poder público via bolsas, programas de inclusão, de ações afirmativas, entre outros (TARÁBOLA, 2015).

Seja via participação em cursinhos pré-vestibulares populares localizados dentro do próprio campus universitário e voltados para estudantes de escola pública de baixa renda, seja ainda por meio de atividades em escolas da rede 
pública de ensino de seus próprios bairros de origem (muitas vezes localizados à grande distância da universidade), como oferta de aulas de reforço de Matemática e Ciências ou divulgação das questóes relacionadas ao acesso e à permanência no ensino superior, a atuação de alguns desses universitários pesquisados em coletivos de estudantes dedicados ao trabalho voluntário é marcadamente limitada pela questão temporal: encontram-se no dilema da premência das demandas materiais ante a queixa de falta de tempo para dedicação aos estudos e às tarefas universitárias, relatam não ter atividades de lazer, no entanto, mesmo assim, assumem compromissos e responsabilidades decorrentes de uma causa coletiva.

Esses jovens universitários que venceram diversas dificuldades para passarem em exames vestibulares concorridíssimos são marcados pelo sobretrabalho, um trabalho sem fim travestido de estudo infinito que, muitas vezes, levou ao abandono de atividades de lazer ou de convívio com amigos. Em suas configuraçóes extremas, esse tipo de superocupação levou-os a tratar a mera possibilidade de ter tempo livre para si como uma espécie de utopia individual, situação desejada, mas impossível de ser alcançada. Tantas renúncias podem configurar redução do indivíduo a alguns domínios da vida, gerando um desequilíbrio individual que caracterizaria uma subjetividade amputada (ARAUJO \& MARTUCCELLI, 2012, p. 201).

Assim, a participação em projetos oriundos de entidades estudantis e voltados a alunos de escolas públicas por estudantes universitários com histórico de baixa sociabilidade e grande enquadramento doméstico e familiar passa pela percepção de se sentirem devedores e por almejarem contribuir com alguma ação de transformação social. Ela se efetiva pela oferta de trabalho voluntário pontual, ligado à realizaçáo de alguma tarefa específica que náo demanda muito daquilo que percebem ser o que mais falta para o bom desempenho na universidade: tempo. Tempo este, aliás, que, em nome da dedicação aos estudos e à vida acadêmica e da adesão a uma causa coletiva próxima à de um ativista pragmático (e distante de um militante ideologizado), falta para a satisfação das demandas econômicas. Os jovens contam com bolsas de estudo, moradia e alimentação oferecidas pela universidade e mantêm, portanto, em alguma medida, a tensa autonomia relativa no tocante à família (DE SINGLY, 2004).

Tem-se, assim, entre esses indivíduos, formas de participação aberta que não restringem outras opçóes futuras, nem "capturam" o presente, deixando margem para continuarem a investir nos estudos universitários sem comprometer seu rendimento acadêmico. Ao contrário, em vez de ameaçar, a participaçáo em diversas instâncias associativas voltadas a um público externo a esse contexto os aproxima de noutros estudantes da universidade e os leva a dialogar com as normas e os códigos dessa nova situação, corroborando a tese de que esses novos estudantes adotam novas práticas coletivas e de ativismo (SPOSITO; BRENNER; MORAES, 2009). 


\section{Considerações finais}

Os exemplos aqui citados não são exaustivos nem se excluem mutuamente, pois podem permitir arranjos que compóem traços comuns presentes com maior ou menor intensidade nas entrevistas. Trata-se, sobretudo, de apresentar de modo heurístico alguns traços dominantes que percorrem as narrativas dos jovens universitários, favorecendo a ampliação do horizonte das investigaçóes e buscando superar dicotomias e polarizaçóes que atravessam muitos dos discursos contemporâneos recobrindo pares como: egoísmo e altruísmo, engajamento e desengajamento, ativismo e passividade, entre outros.

Por outro lado, as noçóes de participação, engajamento e desengajamento demandam contínua revisão, de modo a captar sob o ponto de vista analítico a dinâmica de processos que se apresentam mais como continuum do que oposiçốes estabelecidas, principalmente se considerarmos essas dimensóes da afiliação à esfera público-política no percurso de vida, no caso específico na experiência juvenil.

O clima de polarização e de radicalização argumentativa, muito forte no Brasil contemporâneo, exige a procura de novas categorias que possam de algum modo ampliar a compreensão desses processos que vinculam os indivíduos aos espaços públicos e à política.

Para além da pesquisa sobre o conteúdo das ideias, das estratégias e táticas a serem defendidas nos mais variados coletivos de jovens no interior da experiência universitária, abre-se um espaço analítico relevante se forem levadas em conta duas contribuições traçadas em momentos históricos diversos, mas igualmente importantes. De um lado, a proposta de Lechner, que é a de explorar a dimensão cultural da política, aludindo ao caráter político da convivência social. Remete-se, assim, à experiência subjetiva do "nós" e de nossas capacidades para organizar as formas como queremos conviver, as definiçōes do que significa "viver junto", mantendo o olhar com ênfase nas coordenadas que delimitam o campo público-político e em segundo plano a descrição das posições programáticas (LECHNER, 2007, p. 484).

Nesse sentido, a discussão sobre o agir político pode ainda considerar outra dimensão, a implicação afetiva. Segundo Martuccelli, trata-se de uma forma de implicação caracterizada pela experiência de ser afetado de uma maneira estrutural e bastante personalizada pela vida social que não é nem aquela da participação, tampouco a do engajamento, embora eles possam ser uma das expressóes da sensaçáo individual de ser parte de um coletivo. A proposta do sociólogo é analisar a generalização atual da afetividade implicativa vivida quase sem mediação com os fatos do mundo que faz com que o indivíduo, "antes mesmo de ser um ator, se sente exposto e desafiado pela vida social" (MARTUCCELLI, 2016, p. 4), pois 
essa afetividade denota outro modo de estar no mundo que náo apenas precede, como pode até mesmo se abster da participação e do engajamento. Se, por um lado, "no caso do engajamento e da mobilização a questão é compreender como e por que alguém vai da defesa de seus 'interesses' pessoais a levar em conta o interesse do coletivo ou em todo caso a defesa coletiva de seus interesses", no caso da afetividade "a questão é compreender a experiência implicada na vida social que se esconde atrás de uma relação passiva com a política e com a ação coletiva" (MARTUCCELLI, 2016, p. 6).

\section{Notas}

1. Entre os quais, destacam-se, por exemplo, a análise histórica feita por José Luis Sanfelice (1986) sobre a União Nacional dos Estudantes (UNE) e sua participação em diferentes momentos políticos do país, sobretudo no que tange à resistência do movimento estudantil à ditadura militar no Brasil, além dos estudos desenvolvidos por J. A. Guilhon Albuquerque acerca da América Latina (1977).

\section{Referências}

ALBUQUERQUE, J. A. G. Movimento estudantil e consciência social na América Latina. Rio de Janeiro: Paz e Terra, 1977.

ALMEIDA, A. M. F.; ERNICA, M. Inclusão e segmentação social no ensino superior público no estado de São Paulo (1990-2012). Educação e Sociedade, Campinas, v. 36, n. 130, jan./mar. 2015.

ALMEIDA, W. M. Esforço contínuo: estudantes com desvantagens socioeconômicas e educacionais na USP. Dissertação (Mestrado) - Faculdade de Filosofia, Letras e Ciências Humanas, Universidade de São Paulo, São Paulo, 2006.

ARAUJO, K.; MARTUCCELLI, D. Desafios comunes: retratos de la sociedad chilena y sus individuos. Neoliberalismo, democratización y lazo social. Santiago: LOM, 2012. v. 1.

ARRETCHE, M. (Org.). Trajetórias das desigualdades: como o Brasil mudou nos últimos cinquenta anos. São Paulo: Editora da Unesp, 2015.

AVRITZER, L. Conferências nacionais: ampliando e redefinindo os padróes de participação social no Brasil. Texto para Discussão IPEA, Rio de Janeiro, n. 1.739, maio 2012. Disponível em: <http://www.ipea.gov.br/participacao/images/pdfs/td 1739.pdf>. Acesso em: 15 set. 2015.

AVRITZER, L. Um balanço da participação social no Brasil pós-Constituição de 1988. In: (Org.). Experiência democrática, sistema político e participação popular. São Paulo: Fundaçáo Perseu Abramo, 2013.

; SANTOS, B. S. Introdução. Para ampliar o cânone democrático. In: SANTOS, B. S. Democratizar a democracia. Rio de Janeiro: Civilização Brasileira, 2002. 
BAQUERO, M; BAQUERO, R. Novos padrões de participação política dos jovens na democracia brasileira? Em Debate, Belo Horizonte, v. 4, n. 8, p. 19-25, 2012.

BARGEL, L. Socialisation politique. Dictionnaire genre \& science politique, 2013. p. 468480. Disponível em: <https://halshs.archives-ouvertes.fr/halshs-00869413>. Acesso em: 7 abr. 2016.

BECQUET, V.; DE LINARES, C. (Orgs.). Quand les jeunes s'engagent: entre expérimentations et constructions identitaires. Paris: L'Harmattan, 2005.

BRENNER, A. K. Experiência militante e repercussóes em outras esferas da vida: jovens engajados em partidos políticos. Revista NUPEM, Campo Mourão, v. 6, n. 10, p. 79-93, jan./jun. 2014.

BRINGEL, B. Ciclos de protesto e lutas estudantis no Brasil. Perspectiva Histórica, v. 2, n. 2, p. 29-43, 2012.

. O futuro anterior: continuidades e rupturas nos movimentos estudantis do Brasil. Eccos Revista Cientifica, São Paulo, v. 11, n. 1, p. 97-121, 2009.

CEFAÏ, D.; CARREL, M.; TALPIN, J.; ELIASOPH, N.; LICHTERMAN, P. Ethnographies de la participation. Participations, n. 4, p. 7-48, 2012. Disponível em: <www.cairn.info/ revue-participations-2012-3-page-7.htm>. Acesso em: 2 maio 2016.

CICHELLI, V. The contemporary engagement of young people in France: normative injunctions, institutional programs and the multiplying forms of grouping. Italian Journal of Sociology of Education, n. 2, 2009. Disponível em: shttp://ijse.padovauniversitypress.it/ system/files/papers/2009 2 4.pdf >. Acesso em: 2 abr. 2015.

COULON, A. Le métier d'étudiant: l'entrée dans la vie universitaire. 2. ed. Paris: Economica, 2005.

DAGNINO, E.; OLIVERA, A. J.; PANFICHI, A. Para uma outra leitura da disputa pela construção democrática na América Latina. In: . (Orgs.). A disputa pela construção democrática na América Latina. São Paulo/Campinas: Paz e Terra/Editora da Unicamp, 2006.

DANILIAUSKAS, M. Não se nasce militante, torna-se: processo de engajamento de jovens LGBT - panorama histórico na cidade de São Paulo e cenário atual em Paris. Tese (Doutorado em Educação) - Faculdade de Educação, Universidade de São Paulo, São Paulo, 2016.

DE SINGLY, F. La spécificité de la jeunesse. In: DUBET, F.; GALLAND, O.; DESCHAVANNE, E. (Orgs.). Revue de philosofie et de sciences sociais. Comprendre les jeunes. Paris: PUF, 2004. n. 5. p. 259-273.

ELIAS, N. A sociedade dos indivíduos. Rio de Janeiro: Jorge Zahar, 1994.

Avoiding politics: how Americans produce apathy in everyday life. Nova York: Cambridge University Press, 1998.

ERLICH, V. Les nouveaux étudiants: un groupe social en mutation. Paris: Armand Colin, 1998. 
FELOUZIS, G. La condition étudiante: sociologie des étudiants et de l'université. Paris: PUF, 2001.

FORACCHI, M. A juventude na sociedade moderna. São Paulo: Pioneira, 1972. O estudante e a transformação da sociedade brasileira. São Paulo: Companhia Nacional, 1965.

GRANJON, F. L'internet militant: mouvement social et usages des réseaux télématiques. Rennes: Apogée, 2001.

GROPPO, L. A. Formação política e juventude segundo organizaçóes estudantis em uma universidade do interior de Minas Gerais. In: Reunião Científica Regional Sudeste da ANPEd, 12., Vitória, 2016. Anais... Vitória: Universidade Federal do Espírito Santo, 2016. p. 282-296. Disponível em: <http://verkn.com.br/ebook_comunicacao.pdf>. Acesso em: ago. 2016.

GROPPO, L.A.; ZAIDAN FILHO, M.; MACHADO, O. L. (Orgs.). Juventude e movimento estudantil: ontem e hoje. Recife: Editora Universitária da UFPE, 2008. v. 1.

HONNETH, A. Luta por reconhecimento: a gramática moral dos conflitos sociais. São Paulo: 34, 2003.

IANNI, O. O jovem radical. In: BRITO, S. (Org.). Sociologia da juventude I. Rio de Janeiro: Jorge Zahar, 1968. p. 225-242.

ION, J. L'engagement questionné: enjeux, évolutions, redéfinitions. In: BECQUET, V.; DE LINARES, C. (Orgs.). Quand les jeunes s'engagent: entre expérimentations et constructions identitaires. Paris: L'Harmattan, 2005.

. S'engager dans une société d'individus. Paris: Armand Colin, 2012.

ION, J.; RAVON, B. Causes publiques, affranchissement des appartenances et engagement personnel. Lien Social et Politiques, n. 39, p. 59-71, 1998. Disponível em: shttp://www.erudit.org/revue/lsp/1998/v/n39/005129ar.html>. Acesso em: abr. 2016

KAUFMANN, J-C. L'entretien compréhensif. Paris: Nathan, 1996.

KEMP, K. Grupos de estilo jovens: o rock underground $e$ as práticas (contra)culturais dos grupos "punk" e "thrash" em Sáo Paulo. Dissertação (Mestrado) - Departamento de Antropologia, Universidade Estadual de Campinas, Campinas, 1993.

LECHNER, N. Obras escogidas. Santiago: LOM, 2007. v. 2.

LEFORT, C. A invenção democrática: os limites da dominação totalitária. São Paulo: Brasiliense, 1983.

LÜCHMANN, L. H. H. Abordagens teóricas sobre o associativismo e seus efeitos democráticos. Revista Brasileira de Ciências Sociais, v. 29, n. 85, jun. 2014.

Associativismo e democracia no Brasil contemporâneo. Em Debate, Belo Horizonte, v. 3, n.4, p. 44-51, dez. 2011. 
MARTUCCELLI, D. Cambio de rumbo. Santiago: LOM, 2007.

- ¿Existen individus en el Sur? Santiago: LOM, 2010.

. Grammaires de l'individu. Paris: Gallimard, 2002.

. La consistance du social: une sociologie pour la modernité. Rennes: PUR, 2005.

. L'affectivité implicative et la vie en societé. Quaderni di Teoria Sociale, n. 1, 2016. (mimeo.)

MAUSS, M. Sociologia e antropologia. São Paulo: Cosac Naify, 2003.

MELUCCI, A. Juventude, tempo e movimentos sociais. Revista Brasileira de Educação, n. 5/6, p. 5-14, 1997.

MUXEL, A. Continuidades y rupturas de la experiencia política juvenil. Revista de Estudios de Juventud, n. 81, p. 31-43, jun. 2008.

- Jovens dos anos 90: à procura de uma política sem rótulos. Revista Brasileira de Educação, n. 5/6, p. 151-166, 1997.

PASSERON, J.-C. Attention aux excès de vitesse. Le "nouveau" comme concept sociologique. Esprit, n. 125, p. 129,134, abr. 1987.

PIOTTO, D. As exceçóes e suas regras: estudantes das camadas populares em uma universidade pública. Tese (Doutorado) - Instituto de Psicologia, Universidade de São Paulo, 2007.

POCHMANN, M. Desigualdade econômica no Brasil. São Paulo: Saber Livros, 2015.

RANCIÈRE, J. O desentendimento: política e filosofia. São Paulo: 34, 1996.

O ódio à democracia. São Paulo: Boitempo, 2014.

ROSANVALLON, P. Democracia y desconfianza. Revista de Estudios Políticos, Madri, n. 134, p. 219-237, dez. 2006. Disponível em: <dialnet.unirioja.es/descarga/ articulo/2210465.pdf>. Acesso em: 21 mar. 2016.

SANFELICE, J. L. Movimento estudantil: a UNE na resistência ao golpe de 1964. São Paulo: Cortez, 1986.

SAWICKI, F; SIMÉANT, J. Inventário da sociologia do engajamento militante: nota crítica sobre algumas tendências dos trabalhos franceses. Sociologias, Porto Alegre, ano 13, n. 28, p. 200-255, set./dez. 2011.

SINGLY, F. Las formas de terminar y de no terminar la juventud. Revista de Estudios de Juventud, Madri, n. 71, p. 111-121, dez. 2005.

SORJ, B.; MARTUCCELLI, D. El desafio latinoamericano: cohesión social y democracia. Buenos Aires: Siglo XXI, 2008.

SOUSA, J. T. P. A experiência contemporânea da política entre jovens do sul do Brasil. Buenos Aires: Flacso, 2014. Disponível em: shttp://biblioteca.clacso.edu.ar/clacso/ becas/20140623015303/RELATORIOJaniceTirelli.pdf $>$. Acesso em: 21 nov. 2015. 
SPOSITO, M. P. Ação coletiva, jovens e engajamento militante. In: CARRANO, P.; FÁVERO, O. Narrativas juvenis e espaços públicos: olhares de pesquisas em educação, mídia e ciências sociais. Niterói: Editora da UFF, 2014.

SPOSITO, M.P.; BRENNER, A. K.; MORAES, F. F. Estudos sobre jovens na interface com a política. In:___ (Org.). O estado da arte sobre juventude na pós-graduaçâa brasileira: educação, ciências sociais e serviço social (1999-2006). Belo Horizonte: Argumentum, 2009. v. 2. p. 175-212.

TARÁBOLA, F. S. Aspirantes: desafios de estudantes da USP egressos de escolas públicas no contexto do novo tensionamento politico social brasileiro. Tese (Doutorado) - Faculdade de Educação, Universidade de São Paulo, São Paulo, 2015.

. Quando o ornitorrinco vai à universidade - trajetórias de sucesso e longevidade escolares pouco prováveis na USP: escolarização e formação de habitus de estudantes universitários das camadas populares. Dissertação (Mestrado) - Faculdade de Educação, Universidade de São Paulo, São Paulo, 2010.

TILLY, C. Democracia. Petrópolis: Vozes, 2013.

WEBER, M. A política como vocação. In: MILLS, C. W.; GERTH, H. H. Ensaios de sociologia. Rio de Janeiro: LTC, 1982.

Recebido em 4 de julho de 2016.

Aprovado em 27 de setembro de 2016. 